\title{
Pfaffia paniculata (Brazilian ginseng) extract modulates Mapk and mucin pathways in intestinal inflammation
}

\author{
C.A.R.A. Costa, A.E.V. Quaglio, L.C. Di Stasi* \\ Laboratory of Phytomedicines, Pharmacology and Biotechnology (PhytoPharmaTech), Department of Pharmacology, Institute of Biosciences, São Paulo State University \\ (UNESP), P.O. Box 510, 18618-970 Botucatu, São Paulo, Brazil
}

\section{A R T I C L E I N F O}

\section{Keywords:}

Intestinal inflammation

Mapk

Mucins

Pfaffia paniculata

\begin{abstract}
A B S T R A C T
Ethnopharmacological relevance: Pfaffia paniculata is an endemic Brazilian plant traditionally used against fatigue, stress, inflammation and low immune system as well as with proven intestinal anti-inflammatory activity. Aim of the study: To evaluate intestinal anti-inflammatory effects of $P$. paniculata on the mRNA abundance of Hsp70, Heparanase, Mapk1, Mapk3, Mapk6, Mapk9, Muc1, Muc2, Muc3, Muc4, and NF-кB, as well as the mucin content in colonic samples.

Material and methods: Intestinal inflammation was induced by TNBS and rats were divided into groups that received vehicle or $25,50,100$, or $200 \mathrm{mg} / \mathrm{kg}$ of $P$. paniculata extract, p.o., started $2 \mathrm{~h}$ after inflammation induction and continued daily for 7 days. At the end of the procedure, the animals were killed and their colon samples were obtained for RT-qPCR analysis and mucin histochemical study with PAS/Alcian blue stain. The inflammatory process was confirmed with colon macroscopic analysis and myeloperoxidase (MPO) activity.

Results: P. paniculata at $200 \mathrm{mg} / \mathrm{kg}$ significantly decreased macroscopic damage score, extension of lesion and colonic MPO activity. Besides, P. paniculata at a dose of $25 \mathrm{mg} / \mathrm{kg}$ was also able to significantly decrease Hsp70, while treatment with $50 \mathrm{mg} / \mathrm{kg}$ reduced Mapk3 and increased Muc4. At dose of $100 \mathrm{mg} / \mathrm{kg} P$. paniculata increased Mapk1, Muc3, Muc4, and decreased Mapk3. Finally, at the $200 \mathrm{mg} / \mathrm{kg}$ P. paniculata reduced Mapk3. The heparanase, NF-кB, Mapk6, Mapk9, Muc1 and Muc2 mRNA abundances were not altered after P. paniculata treatments.

Conclusion: Intestinal anti-inflammatory activity of $P$. paniculata was related to modulation of Mapks and mucin gene expression, as well as mucus secretion in intestinal inflammation.
\end{abstract}

\section{Introduction}

Inflammatory bowel disease (IBD) is a chronic and relapsing inflammation of gastrointestinal tract, including ulcerative colitis and Chron's disease. In these diseases, mucus layer provides the first line of defence and protective function of the intestinal mucosal barrier, which depends on the coordinated regulation of the mucus layer, epithelial cells and immune response (Dorofeyev et al., 2013). In addition, mitogen-activated protein kinases (MAPKs) signalling, heparanase, NF- $\mathrm{KB}$ and heat shock proteins (HSPs) have been closely related to inflammatory process induced by TNBS in rats (Quaglio et al., 2015a, 2015b).

Pfaffia paniculata (Martius) Kuntze, Amaranthaceae (Brazilian ginseng) is a medicinal Brazilian endemic plant traditionally used as tonic, invigorating, anti-stress, aphrodisiac, memory booster and to treat rheumatism, arthritis and ulcers (de Oliveira, 1986; Elkins, 1997; Mendes and Carlini, 2007; Rates and Gosmann, 2002). In previous study, we demonstrated that $P$. paniculata extract is an intestinal antiinflammatory and immunomodulatory product that acts reducing colonic levels of IL-1 $\beta$, INF- $\gamma$, IL- 6 and TNF- $\alpha$, and modulating oxidative stress in TNBS-model of intestinal inflammation (Costa et al., 2015). These results encouraged us to study whether intestinal anti-inflammatory effects of $P$. paniculata is related to mucus secretion and modulation of Hsp70, heparanase, Mapks, Muc1, Muc2, Muc3, Muc4, and NF-KB gene expression.

\footnotetext{
Abbreviations: Gapdh, Glyceraldehyde-3-phosphate dehydrogenase; HPLC, High performance liquid chromatography; Hprt1, Hypoxanthine phosphoribosyltransferase 1; HSP, Heat

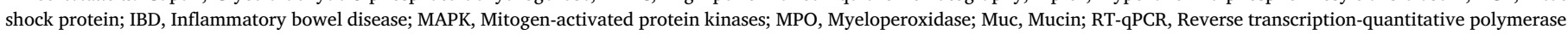
chain reaction; TNBS, 2,4,6-Trinitrobenzenesulfonic acid

* Corresponding author.

E-mail address: ldistasi@ibb.unesp.br (L.C. Di Stasi).
} 
Table 1

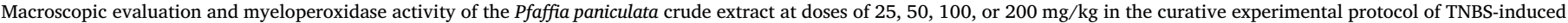
intestinal inflammation in rats.

\begin{tabular}{|c|c|c|c|c|c|c|}
\hline Model & \multicolumn{2}{|c|}{ Groups } & $\begin{array}{l}\text { Macroscopic } \\
\text { damage score } \\
(0-10(\mathrm{IQR}))^{1}\end{array}$ & $\begin{array}{c}\text { Extent of } \\
\text { lesion }(\mathrm{cm})^{2}\end{array}$ & $\begin{array}{l}\text { Weight/length } \\
\text { ratio }(\mathrm{mg} / \mathrm{cm})^{2}\end{array}$ & $\begin{array}{c}\text { Colonic } \\
\text { myeloperoxidase } \\
(\mathrm{MPO}) \text { activity }(\mathrm{U} / \mathrm{g})^{2}\end{array}$ \\
\hline \multirow{6}{*}{$\begin{array}{l}\text { Curative } \\
\text { Protocol }\end{array}$} & \multicolumn{2}{|c|}{ TNBS control (6) } & $7(6-8)$ & $2.93 \pm 0.3$ & $213.6 \pm 45.3$ & $912.3 \pm 212.4$ \\
\hline & \multicolumn{2}{|c|}{ Non-colitic (6) } & $0 * *$ & $0 * *$ & $89.9 \pm 2.4^{* *}$ & $82.9 \pm 10.3^{* *}$ \\
\hline & \multirow{4}{*}{$\begin{array}{c}\text { Pfaffia } \\
\text { paniculata } \\
\mathrm{mg} / \mathrm{kg}(\mathrm{n})\end{array}$} & $25(6)$ & $6.5(5.75-7)$ & $2.25 \pm 0.3$ & $166.3 \pm 5.9$ & $549.0 \pm 110.2$ \\
\hline & & $50(6)$ & $6(4-8)$ & $2.13 \pm 0.6$ & $191.7 \pm 25.7$ & $600.1 \pm 157.7$ \\
\hline & & $100(6)$ & $5(5-6)$ & $1.87 \pm 0.2$ & $169.3 \pm 27.8$ & $536.9 \pm 56.5$ \\
\hline & & $200(6)$ & $4.5(1-5.25)^{* *}$ & $1.15 \pm 0.4^{* *}$ & $150.8 \pm 7.1$ & $376.2 \pm 95.9 * *$ \\
\hline
\end{tabular}

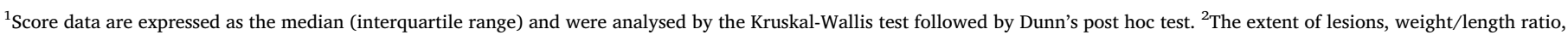

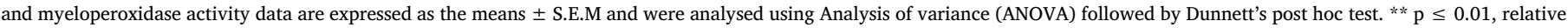
to the TNBS control.

\section{Material and methods}

2.1. Plant material, extract preparation, phytochemical analysis and total phenolic content

P. paniculata roots were collected in Chemical, Biological and Agricultural Pluridisciplinary Research Centre - Paulínia/SP (September 2011), and a voucher specimen (CPQBA 0241) was kept in the herbarium. The preparation of plant material, the extraction method (cold maceration with $70 \%$ methanol for $48 \mathrm{~h}$ ), lyophilisation and phytochemical analysis (qualitative phytochemical screening, thin layer chromatography, high-performance liquid chromatography), were performed according to Costa et al. (2015). The total phenolic content was determined by reaction with Folin-Ciocalteu reagent adapted to a 96-well plate (Singleton et al., 1999) and the reactions in the plate were observed using a UV-Vis spectrophotometer (Power wave 340 , Bio-TEK) at $750 \eta \mathrm{m}$.

\subsection{Intestinal inflammation assessment}

Male Wistar rats (weighing 180-220 g) were obtained from ANILAB, Paulínia/SP, Brazil, and housed under standard environmental conditions $\left(21 \pm 2{ }^{\circ} \mathrm{C}\right)$ with 12 -h light/dark cycles, air filtration and free access to water and food. All of the experiments were conducted in accordance with ethical principles adopted by the Brazilian College of Animal Experimentation and approved by the Biosciences Institute Ethics Committee for Animal Research, Protocol number 042/04-CEEA. Intestinal inflammation was induced by method described by Morris et al. (1989) with modifications by Costa et al. (2015). After the animal's death, the colons were weighed and its length measured under a constant load ( $2 \mathrm{~g}$ ), then opened longitudinally and scored for macroscopically visible damage on a $0-10$ scale by one observer unaware of the treatment, according to the criteria previously described (Bell et al., 1995). After that, the colon was divided for MPO activity, RT-qPCR analysis (Gapdh, actin- $\beta$, Hprt1, Hsp70, Heparanase, Mapk1, Mapk3, Mapk6, Mapk9, Muc1, Muc2, Muc3, Muc4, and NF-кB) and mucin histochemical study with PAS/Alcian blue stain.

\subsection{Inflammatory mediator's analysis}

Colon samples (100 mg) were collected in Trizol, homogenized and submitted to total RNA extraction and reverse transcription with SuperScript III (200 U/ml; Life Technologies ${ }^{\mathrm{TM}}$ ) according to the manufacturer's protocol. Primers for targets and reference genes were designed based on the rat sequences (Supplementary material). General procedure for RT-qPCR analysis was detailed described by Quaglio et al. (2015a) and Quaglio et al. (2015b). The relative expression of each target gene was calculated using the DDCt method with efficiency correction (Pfaffl, 2001). Mucin histochemical analysis was performed according to protocol described by Linden et al. (2008).

\subsection{Statistics}

Macroscopic damage score was expressed as the median \pm interquartile range and analysed by the Kruskal-Wallis test followed by Dunn's post hoc test. Parametric results are expressed as the mean \pm S.E.M. Data were analysed using one-way ANOVA followed by Dunnett's Multiple Comparison test. Differences were considered significant when $\mathrm{p} \leq 0.05$.

\section{Results}

Collection of $P$. paniculata provided $1.146 \mathrm{~kg}$ of fresh material, which resulted in $166.38 \mathrm{~g}$ (33.28\%) of lyophilised extract. Phytochemical screening showed that the extract consisted mainly of triterpenes, saponins, total phenolic compounds, flavonoids and alkaloids. The HPLC analysis of the $P$. paniculata hydromethanolic extract demonstrated the presence of nortriterpenic and steroidal saponins (data not shown), as demonstrated in our previous study (Costa et al., 2015). The measurement of total phenols contained in the crude $P$. paniculata extract showed $3.02 \mathrm{mg}$ of gallic acid equivalents (GAE)/g extract.

Inflammatory process was confirmed by presence of lesion extending approximately $3 \mathrm{~cm}$ in the colon and increased MPO activity in TNBS-control group. $P$. paniculata at a dose of $200 \mathrm{mg} / \mathrm{kg}$ was able to decrease macroscopic damage score, extent of lesion and MPO activity (Table 1).

P. paniculata at a dose of $25 \mathrm{mg} / \mathrm{kg}$ was also able to significantly decrease Hsp70, while treatment with $50 \mathrm{mg} / \mathrm{kg}$ reduced Mapk3 and increased Muc4. At dose of $100 \mathrm{mg} / \mathrm{kg}$ P. paniculata increased Mapk1, Muc3, Muc4, and decreased Mapk3. Finally, at the $200 \mathrm{mg} / \mathrm{kg} \mathrm{P.} \mathrm{pa-}$ niculata reduced Mapk3 (Fig. 1). The heparanase, NF-kB, Mapk6, Mapk9, Muc1 and Muc2 mRNA abundances were not altered after $P$. paniculata treatments (data not show).

As see in Fig. 2, in the treated groups with $P$. paniculata, we observed an increase of mucins associated with a higher blue staining and a mucus membrane layer, a membrane-bond mucin.

\section{Discussion}

In previous study we demonstrated that intestinal anti-inflammatory activity of $P$. paniculata was related to reduced oxidative stress and C-reactive protein colonic levels, associated with an immunomodulatory activity as evidenced by reduced colonic levels of IL- 



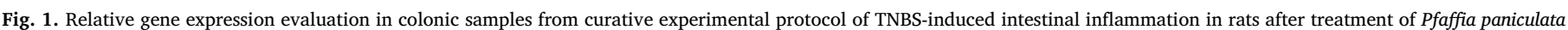

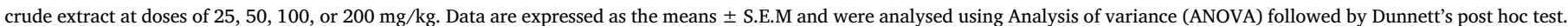
$* \mathrm{p} \leq 0.05$, relative to the TNBS control.

$1 \beta$, INF- $\gamma$, TNF- $\alpha$ and IL-6 (Costa et al., 2015). In this study, we confirmed the extract anti-inflammatory effects by analysing macroscopic parameters and MPO activity as an indicative of neutrophil infiltration. Despite the large use of $P$. paniculata, there are few studies showing its pharmacological effects (Mendes and Carlini, 2007). The plant is rich in pfaffic acid, nortriterpenoid saponins (pfaffosides A, B, C, D, E, and F) and phytosterols such as $\beta$-sitosterol and stigmasterol (Li et al., 2010; Nishimoto et al., 1984). There is a series of studies that demonstrate several biological activities for these substances, such as analgesic, anti- inflammatory, and antitumor (Costa et al., 2015).

Mucosal barrier is the primary barrier protecting the organism against the lumen environment (Goll and van Beelen Granlund, 2015), which is necessary to maintain intestinal homeostasis. Moreover, changes in the mucosal barrier function promote the exposition to luminal content permeability and triggers an immunological response (Michielan and D'Inca, 2015; Sanchez de Medina et al., 2014). IBD patients display several defects in many specialized components of mucosal barrier from the mucus layer composition to the adhesion 


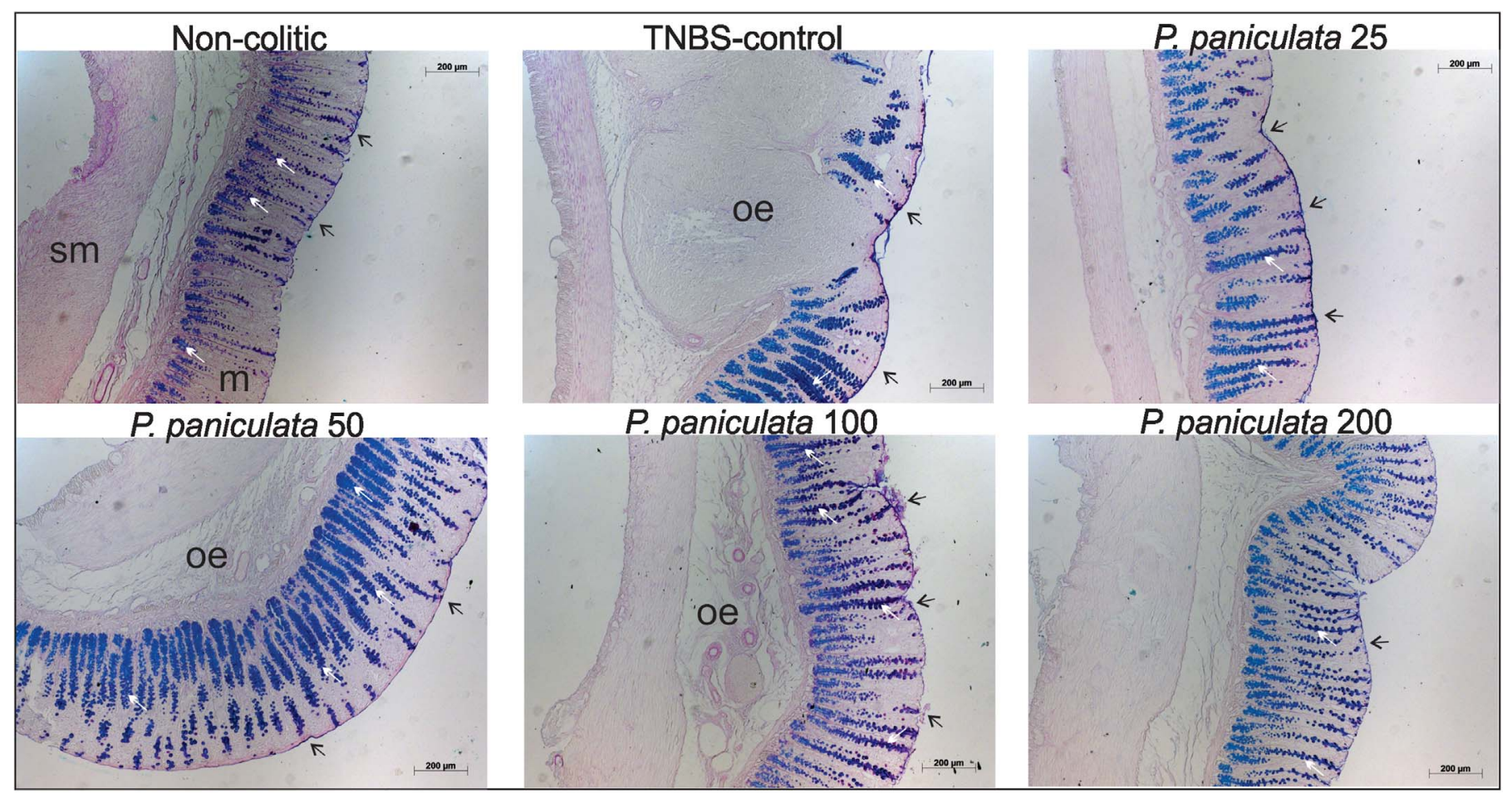

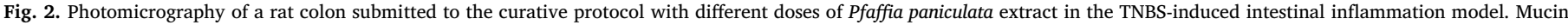
histochemical study performed by PAS/Alcian Blue staining: Mucosa (m); membrane-bond mucins (black arrows); submucosa (sm); oedema (oe); blue staining (white arrows).

molecules that regulate paracellular permeability (Michielan and D'Inca, 2015). Mucus consists of high molecular weight glycoproteins called mucins, which are synthesized and secreted by goblet cells and work primarily to lubricate the epithelium and protect it from noxious substances damage (Cornick et al., 2015).

The histochemical analysis showed an increase in mucus production after administration of 50 and $100 \mathrm{mg} / \mathrm{kg}$ of $P$. paniculata extract, as strongly supported by the increase in gene expression Muc3 and 4 . Recent studies have also suggested the involvement of mucins in complex immune functions such as antigen presentation and tolerance (Cornick et al., 2015). Under normal physiological conditions, goblet cells continually produce mucins to replenish and maintain the mucus barrier. However, goblet cell function can be disrupted by several factors that can affect the integrity of the mucus barrier (Cornick et al., 2015). In addition, Han et al. (2014) demonstrated that Korean ginseng modulates intestinal mucin production by gene expression.

Mapks are a family of serine/threonine kinases with several substrates and involved in a wide range of biological processes as growth, proliferation, differentiation, migration and apoptosis (Chang and Karin, 2001; Dhillon et al., 2007). Recent studies demonstrated that Mapk1, 3, 6 and 9 were altered in response to TNBS instillation (Quaglio et al., 2015b). Although no difference between healthy and TNBS-control animals were observed, we detected that administration of $P$. paniculata extract produces different results, enhancing Mapk1 gene expression after the doses of 50 and $100 \mathrm{mg} / \mathrm{kg}$ and decreasing Mapk3 relative mRNA after 50, 100 or $200 \mathrm{mg} / \mathrm{kg}$ doses. Mapk 1 and 3 have been associated to glutathione (GSH) depletion and myeloperoxidase (MPO) activity enhancement, being correlated with oxidative stress (Hao et al., 2012). GSH depletion and MPO activity enhancement induced by intestinal inflammation were counteracted by treatment with $P$. paniculata at 50 or $200 \mathrm{mg} / \mathrm{kg}$ (Costa et al., 2015). Since $P$. paniculata inhibited Mapk3 expression, it is possible to suggest that Mapk3 gene modulation may be related to lower oxidative stress in treated animals. Besides Mapk6 and 9 participate in TNBS-induced intestinal inflammation (Quaglio et al., 2015b), no alteration was observed after $P$. paniculata crude extract administration, indicating that these two kinases probably did not participate in its anti-inflammatory action.

Although heparanase and NF-кB genes were not altered by $P$. paniculata treatment, its lowest dose was able to inhibit Hsp70 relative mRNA. Hsp70 high concentrations after administration of 50, 100 or $200 \mathrm{mg} / \mathrm{kg}$ doses could be explained by a positive response from the organism with $P$. paniculata treatment. Once Hsp70 accumulation allows it to be readily available to rescue proteins from irreversible damage or to increase its proteolysis (Noonan et al., 2008), it is beneficial against TNBS instillation (Quaglio et al., 2015a).

In conclusion, we demonstrated that intestinal anti-inflammatory activity of $P$. paniculata was related to differential modulation on Mapks and mucin expression and production, with protective effect intestinal barrier function, reinforcing the possible use of this extract as complementary medicine to treat intestinal inflammation.

\section{Acknowledgments}

The authors acknowledge Ilio Montanari Júnior from the CPQBAUNICAMP who provided us with the plant. Celso A.R.A. Costa was the recipient of a fellowship from São Paulo Research Foundation - FAPESP Brazil (2011/50847-4; 2015/15267-8).

\section{Appendix A. Supplementary material}

Supplementary data associated with this article can be found in the online version at http://dx.doi.org/10.1016/j.jep.2017.10.009.

\section{References}

Bell, C., Gall, D., Wallace, J., 1995. Disruption of colonic electrolyte transport in experimental colitis. Am. J. Physiol. 268, G622-G630.

Chang, L., Karin, M., 2001. Mammalian MAP kinase signalling cascades. Nature 410, 37-40.

Cornick, S., Tawiah, A., Chadee, K., 2015. Roles and regulation of the mucus barrier in the gut. Tissue Barriers 3, e982426.

Costa, C.A., Tanimoto, A., Quaglio, A.E., Almeida, L.D., Jr, Severi, J.A., Di Stasi, L.C., 2015. Anti-inflammatory effects of Brazilian ginseng (Pfaffia paniculata) on TNBS- 
induced intestinal inflammation: experimental evidence. Int. Immunopharmacol. 28, 459-469.

Dhillon, A.S., Hagan, S., Rath, O., Kolch, W., 2007. MAP kinase signalling pathways in cancer. Oncogene 26, 3279-3290.

Dorofeyev, A.E., Vasilenko, I.V., Rassokhina, O.A., Kondratiuk, R.B., 2013. Mucosal barrier in ulcerative colitis and Crohn's disease. Gastroenterol. Res Pract. 2013, 431231.

Elkins, R., 1997. Medicinal Herbs of the Rain Forest: Uncovering the Rain Forest's Natural Medicines. Pleasant Grove (UT), Woodland Publishing, pp. 154.

Goll, R., van Beelen Granlund, A., 2015. Intestinal barrier homeostasis in inflammatory bowel disease. Scand. J. Gastroenterol. 50, 3-12.

Han, K.S., Balan, P., Hong, H.D., Choi, W.I., Cho, C.W., Lee, Y.C., Moughan, P.J., Singh, H., 2014. Korean ginseng modulates the ileal microbiota and mucin gene expression in the growing rat. Food Funct. 5, 1506-1512.

Hao, J., Meng, L.Q., Xu, P.C., Chen, M., Zhao, M.H., 2012. p38MAPK, ERK and PI3K signaling pathways are involved in C5a-primed neutrophils for ANCA-mediated activation. PLoS One 7, e38317.

Li, J., Jadhav, A., Khan, I., 2010. Triterpenoids from Brazilian ginseng, Pfaffia paniculata. Planta Med. 76, 635-639.

Linden, S.K., Sutton, P., Karlsson, N.G., Korolik, V., McGuckin, M.A., 2008. Mucins in the mucosal barrier to infection. Mucosal Immunol. 1, 183-197.

Mendes, F., Carlini, E., 2007. Brazilian plants as possible adaptogens: an ethnopharmacological survey of books edited in Brazil. J. Ethnopharmacol. 109, 493500.

Michielan, A., D'Inca, R., 2015. Intestinal permeability in inflammatory bowel disease: pathogenesis, clinical evaluation, and therapy of leaky gut. Med. Inflamm. 2015, 628157.

Morris, G., Beck, P., Herridge, M., Depew, W., Szewczuk, M., Wallace, J., 1989. Hapten- induced model of chronic inflammation and ulceration in the rat colon. Gastroenterology 96, 795-803.

Nishimoto, N., Nakai, S., Takagi, N., Hayashi, S., Takemoto, T., Odashima, S., Kizu, H., Wada, Y., 1984. Pfaffosides and nortriterpenoid saponins from Pfaffia paniculata. Phytochemistry 23, 139-142.

Noonan, E., Giardina, C., Hightower, L., 2008. Hsp70B' and Hsp72 form a complex in stressed human colon cells and each contributes to cytoprotection. Exp. Cell Res. 314, 2468-2476.

de Oliveira, F., 1986. Pfaffia paniculata (Martius) Kuntze: o ginseng-brasileiro. Rev. Bras. Farmacogn. 1, 8692.

Pfaffl, M.W., 2001. A new mathematical model for relative quantification in real-time RTPCR. Nucleic Acids Res. 29, e45.

Quaglio, A.E., Castilho, A.C., Di Stasi, L.C., 2015a. Experimental evidence of heparanase, Hsp70 and NF-kappaB gene expression on the response of anti-inflammatory drugs in TNBS-induced colonic inflammation. Life Sci. 141, 179-187.

Quaglio, A.E., Castilho, A.C., Di Stasi, L.C., 2015b. Experimental evidence of MAP kinase gene expression on the response of intestinal anti-inflammatory drugs. Life Sci. 136, 60-66.

Rates, S., Gosmann, G., 2002. Gênero Pfaffia: aspectos químicos, farmacológicos e implicações para o seu emprego terapêutico. Braz. J. Pharmacogn. 12, 85-93.

Sanchez de Medina, F., Romero-Calvo, I., Mascaraque, C., Martinez-Augustin, O., 2014. Intestinal inflammation and mucosal barrier function. Inflamm. Bowel Dis. 20, 2394-2404.

Singleton, V., Orthofer, R., Lamuela-Raventós, R., 1999. Analysis of total phenols and other oxidation substrates and antioxidants by means of folin-ciocalteu reagent. In: Lester, P. (Ed.), Methods in Enzymology. Academic Press, pp. 152-178. 